Available online @ https://jiem.jnnce.ac.in https:www.doi.org/10.37314/JJEM.2020.050215 Indexed in International Scientific Indexing (ISI) Impact factor: 1.395 for 2021-22 Published on: 31 January 2022

\title{
Study on Efficiency of Fully Wet Porous Trapezoidal Fin Structures in the Presence of Convection and Radiation
}

\author{
B.J. Gireesha ${ }^{1}$, M.L. Keerthi ${ }^{1}$, D.O. Soumya ${ }^{1}$ \\ ${ }^{1 *}$ Department of PG Studies and Research in Mathematics, Kuvempu University, Shankaraghatta-577451, Shivamogga, \\ Karnataka, India.
}

bjgireesu@gmail.com, keerthiholalur@gmail.com, soumyado510@gmail.com

\begin{abstract}
The thermal behaviour of fully wet porous trapezoidal profiled longitudinal fin structures in the presence of natural convection and radiation has been scrutinized in the present analysis. The rectangular and trapezoidal profiles have been comparatively analysed. The Darcy's law has been incorporated to study the solid-fluid interactions. Further, the internal heat generation has been assumed to be a linear function of temperature. The obtained non-linear second order ordinary differential equation has been reduced and evaluated numerically. The impact of fully wet condition, porous nature, internal heat generation and other relevant parameters on the thermal profile and efficiency of trapezoidal and rectangular fin profiles has been interpreted graphically and discussed. It has been derived that the rectangular fin profile is more efficient than the trapezoidal profile.
\end{abstract}

Keywords: Natural convection, porous, trapezoidal profile, fully wet longitudinal fin, fin efficiency, internal heat generation.

\section{Introduction}

The fin, which is an extra surface attached to the primary surface, is significant in amplifying the cooling process. Fin structures are generally applied in the engineering field to improve heat transfer rates by expanding surface area and adding material attachment. In their work, Kraus et al [11] have comprehensively covered the basic concepts regarding the extended surface heat transfer.

Porous fin is implemented to extend the surfaces of a system, resulting in effective heat transfer amplification. Hence Kiwan and $\mathrm{Al}$ Nimr [9] provided a unique technique that uses porous fins to improve heat transmission from a given surface. Kiwan [10] explored the role of radiation heat transfer on a convective porous extended surface with respect to a vertical isothermal surface. The Darcy model was used by Gorla and Bakier [4] to examine the thermal performance of extended porous surface of rectangular profile. To solve a model representing heat transport in a radial porous fin, Jooma and Harley [6] used the CrankNicolson technique. Sobamowo et al [18] used the developed exact results to examine the impact of thermal-model factors on the permeable fin's energy performance. MartinsCosta et al [13] used the Oberbeck-Boussinesq approximation with Darcy's law to scrutinize the thermal profile of a porous rectangular fin.

The wetted fin, as opposed to a dry one, allows for greater heat circulation. As a result, the totally wet situation has piqued people's attention, and numerous works have been conducted as a result. Hatami and Ganji [5] investigated the mass and heat transfer in a porous radial wet fin by $4^{\text {th }}$ order Runge Kutta and Least Square method and the impact of Darcy number on the energy field has also been investigated. The radiation heat transfer in the permeable fully wet fin has been studied by Darvishi et al [2]. The Darcy model was 
used to formulate the energy equation in this research. Panda et al [15] used the Homotopy analysis technique to obtain the closed form solution for analysing the energy profile of a wet fin with variable properties. The heat increase in longitudinal, and pin wet fins was studied by Kundu et al [12]. They also examined the non-Fourier and Fourier heat transfer effects with varying conditions and wet fin design variables. The effect of porous wet factor on the energy profile of the wet fin was observed by Sowmya et al [19]. They noticed that as the permeability wet parameter is improved, the thermal energy of the fin surface diminishes.

Fins have been influenced by a variety of applications, including aircraft engines, gas turbines, radiators, electrical semiconductors, and automobiles. There is a demand for a lighter, more efficient, and cost-effective fin. As a result, numerous academicians are interested in studying fin efficiency. Torabi et al. [20] used the technique of differential transformation to examine the thermal performance of a longitudinal radiativeconvective fin, and they presented the fin efficiency to evaluate the performance of concave parabolic and trapezoidal fin profiles as compared to rectangular fin's performance. Sheik et al [17] examined how to improve heat transmission in pin fins and concluded that fin made up of aluminium is more efficient than other materials. According to the findings of Al-Fahed and Alasfour [1], short fins give extra fin efficiency at constant cross-sectional area, and efficiency declines as modified Biot number increases. The authors Purwadi et al [16] have concluded that in the investigation of effectiveness and efficiency of the fin in unsteady flow condition, higher the heat flow rate, higher the fin's effectiveness, and efficiency.

Khani and Aziz [8] developed an exact result for the thermal performance of longitudinal fin of trapezoidal profile with energy dependent thermal conductivity and heat transfer coefficient using the homotopy analysis technique. The two-dimensional analysis of inverted trapezoidal fin profiles with varying fin base thickness is presented by Kang [7]. They noticed that as the fin shape factor is enhanced, heat loss decreases linearly. The temperature profile of the trapezoidal extended surface was studied by Das [3]. This research also found that fin size, as well as the coefficient of thermal conductivity, used to have a greater impact on temperature diffusion than other variables. Turkyilmazoglu [21] investigated heat transfer improvement on a moving extended surface with a trapezoidal cross section. Onah et al [14] developed the trapezoidal plate fin to study the heat exchanger's efficiency. They also observed that changing the rate of mass flow improves the heat exchanger's efficiency.

Recognizing the importance of the field, we planned to investigate the heat transmission through the porous trapezoidal fin in a fully wet environment. The radiation and natural convection effects have been considered as well. Numerical solutions have been found for the governing dimensionless differential equation and the physical relevance of the relevant parameters has been shown in graphs and physically interpreted. The gravity of the present study comes to surface in the design and manufacture of fin structures.

\section{Governing Equations and Physical Model}

A longitudinal fin of trapezoidal profile as depicted in figure 1 has been considered for the analysis. The fin structure of length $L$, width $w$ and base thickness $t_{b}$ is mounted on a primary surface at temperature $T_{b}$. The solid matrix is porous in nature and is fully wetted in a fluid at temperature $T_{a}$. The heat enters the fin at the base and is lost via convective and radiative heat losses to the ambience. Here, the internal heat generation is linearly dependent with respect to temperature. Further, the following assumptions have been made: the heat transfer in the fin is considered one-dimensional, the fin is saturated and is in thermal equilibrium with the fluid in the surrounding, the fin material is isotropic and homogeneous, and the surface emissivity and 
thermal conductivity of the fin are assumed assumptions is given by, constant throughout the length of the fin.

The steady-state energy balance for the trapezoidal fin under the above-mentioned
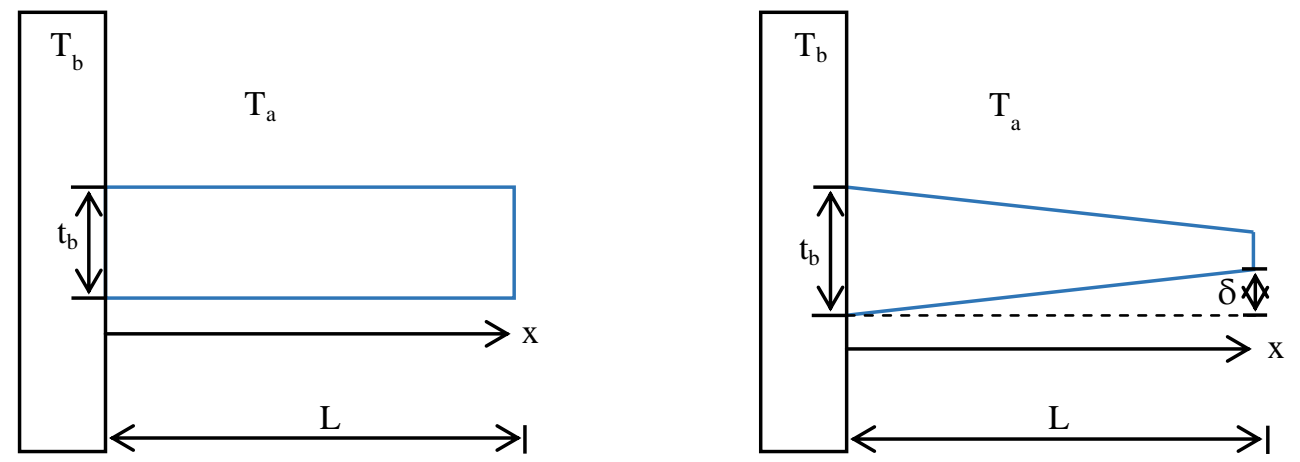

Figure 1: Geometry of rectangular and trapezoidal fin profiles

$$
\begin{aligned}
& \frac{d}{d x}\left(k_{e f f} A_{c}(x) \frac{d T}{d x}\right)-2 \varepsilon \sigma W d x\left(T^{4}-T_{a}^{4}\right) \\
& -2 \dot{m} C_{p}\left(T-T_{a}\right)-2 h_{D} W d x i_{f g}\left(w-w_{a}\right)(1-\phi) \\
& -2 h(T)(1-\phi) W d x\left(T-T_{a}\right)+q^{*}(T) A_{c}(x)=0 .(1)
\end{aligned}
$$

The variable area of cross-section is given by,

$$
A_{c}(x)=W t(x)
$$

Here, $t(x)$ is the local fin thickness of the trapezoidal profile given by,

$$
t(x)=t_{b}-\delta\left(\frac{x}{L}\right)
$$

According to Darcy's law, the mass flow rate of fluid through the porous fin structure is given by,

$$
\dot{m}=\rho v(x) W d x .
$$

Where, $v(x)$ is the passage velocity given by,

$$
v(x)=\frac{g K \beta_{f}\left(T-T_{a}\right)}{v_{f}} .
$$

The temperature sensitive internal heat generation and convective heat transfer coefficient $h$ are given by,

$$
\begin{aligned}
& q^{*}(T)=q_{a}^{*}\left(1+\epsilon_{g}\left(T-T_{a}\right)\right), \\
& h(T)=h_{a}\left(\frac{T-T_{a}}{T_{b}-T_{a}}\right)^{m}=h_{D} C_{p} L e^{\frac{2}{3}} .
\end{aligned}
$$

On simplifying the equation obtained by substituting the equations (2)-(7) in equation (1), we get,

$$
\begin{aligned}
& k_{e f f} \frac{d}{d x}\left[\left(t_{b}-\delta\left(\frac{x}{L}\right)\right) \frac{d T}{d x}\right]-\frac{2(1-\phi) h_{a}\left(T-T_{a}\right)^{m+1}}{\left(T_{b}-T_{a}\right)^{m}} \\
& +q_{a}^{*}\left(1+\epsilon_{g}\left(T-T_{a}\right)\right)\left(t_{b}-\delta\left(\frac{x}{L}\right)\right)-2 \sigma \varepsilon\left(T^{4}-T_{a}^{4}\right) \\
& -\frac{2 h_{a} i_{f g}(1-\phi)\left(w-w_{a}\right)\left(T-T_{a}\right)^{m}}{C_{p} L e^{\frac{2}{3}}\left(T_{b}-T_{a}\right)^{m}}-\frac{2 \rho_{f} g K \beta_{f} C_{p}}{v_{f}}\left(T-T_{a}\right)^{2}=0 .
\end{aligned}
$$

The corresponding boundary conditions are,

$$
\begin{aligned}
& T=T_{b} \text { at } x=0, \\
& \frac{d T}{d x}=0 \text { at } x=L .
\end{aligned}
$$

Let us consider the following dimensionless quantities:

$$
\begin{aligned}
& \theta=\frac{T}{T_{b}}, \theta_{a}=\frac{T_{a}}{T_{b}}, X=\frac{x}{L}, N r=\frac{2 \sigma \varepsilon T_{b}^{3} L^{2}}{k_{e f f} t_{b}}, C=\frac{\delta}{t_{b}}, \\
& N c=\frac{2 \rho_{f} g \beta_{f} K C_{p} T_{b} L^{2}}{v_{f} k_{e f f} t_{b}}, \epsilon_{G}=\epsilon_{g} T_{b}, G=\frac{q_{a}^{*} L^{2}}{k_{e f f^{T}},} \\
& m_{o}=\frac{2 h_{a} L^{2}(1-\phi)}{k_{e f f} t_{b}}, m_{1}=\frac{2 h_{a} i_{f g} b_{2} L^{2}(1-\phi)}{k_{e f f} t_{b} C_{p} L e^{\frac{2}{3}}}, \\
& m_{2}=m_{o}+m_{1}, w-w_{a}=b_{2}\left(T-T_{a}\right) .
\end{aligned}
$$

Dimensionless form of equation (8) is given by, 


$$
\begin{aligned}
& \frac{d^{2} \theta}{d X^{2}}-C \frac{d \theta}{d X}-C X \frac{d^{2} \theta}{d X^{2}}+G\left(1+\epsilon_{G}\left(\theta-\theta_{a}\right)\right)(1-C X) \\
& -m_{2} \frac{\left(\theta-\theta_{a}\right)^{m+1}}{\left(1-\theta_{a}\right)^{m}}-N c\left(\theta-\theta_{a}\right)^{2}-N r\left(\theta^{4}-\theta_{a}^{4}\right)=0 .
\end{aligned}
$$

Here $C=0$ represents a rectangular profiled fin and $C>0$ represents a trapezoidal profiled fin.

The corresponding boundary conditions are,

$$
\begin{aligned}
& \theta=1 \text { at } X=0, \\
& \frac{d \theta}{d X}=0 \text { at } X=1 .
\end{aligned}
$$

Fin efficiency is one of the important tools to measure the thermal performance of fins. The heat transfer through the fin is given by,

$$
Q_{f}=\int_{0}^{L}\left[\begin{array}{c}
\frac{2 \rho_{f} g K w \beta_{f} C_{p}}{v_{f}}\left(T-T_{a}\right)^{2} \\
+\frac{2 h_{a} i_{f g} w b_{2}(1-\phi)}{c_{p} L e^{\frac{2}{3}}} \frac{\left(T-T_{a}\right)^{m+1}}{\left(T_{b}-T_{a}\right)^{m}} \\
+2(1-\phi) h_{a} w \frac{\left(T-T_{a}\right)^{m+1}}{\left(T_{b}-T_{a}\right)^{m}} \\
+2 \sigma \varepsilon w\left(T^{4}-T_{a}^{4}\right)
\end{array}\right] d x
$$

The heat transfer through an ideal fin is given by,

$Q_{\text {ideal }}=$

$2 \sigma \varepsilon w L\left(T_{b}^{4}-T_{a}^{4}\right)+\frac{2 h_{a} i_{f g} w b_{2}(1-\phi) L}{c_{p} L e^{\frac{2}{3}}}\left(T_{b}-T_{a}\right)$

$+\frac{2 \rho_{f} g K w \beta_{f} C_{p} L}{v_{f}}\left(T_{b}-T_{a}\right)^{2}+2(1-\phi) h_{a} w L\left(T_{b}-T_{a}\right)$.

The fin efficiency can be calculated as,

$$
\eta=\frac{Q_{f}}{Q_{\text {ideal }}} .
$$

The fin efficiency in dimensionless form is given by,

$\eta=\frac{\int_{0}^{1}\left[N c\left(\theta-\theta_{a}\right)^{2}+N r\left(\theta^{4}-\theta_{a}^{4}\right)+m_{2} \frac{\left(\theta-\theta_{a}\right)^{m+1}}{\left(1-\theta_{a}\right)^{m}}\right] d X}{N c\left(1-\theta_{a}\right)^{2}+N r\left(1-\theta_{a}^{4}\right)+m_{2}\left(1-\theta_{a}\right)}$

\section{Solution Methodology}

The equation (11) along with the boundary conditions in equation (12) is a highly nonlinear $2^{\text {nd }}$ order ordinary differential equation. The symbolic software Maple is utilized to solve the equation by administering the efficient Runge-Kutta Fehlberg $4^{\text {th }}-5^{\text {th }}$ order method. The procedure can be envisioned as,

$$
\begin{aligned}
p_{1}= & h f\left(x_{1}, y_{1}\right), \\
p_{2}= & h f\left(x_{1}+\frac{1}{4} h, y_{1}+\frac{1}{4} p_{1}\right), \\
p_{3}= & h f\left(x_{1}+\frac{3}{8} h, y_{1}+\frac{3}{32} p_{1}+\frac{9}{32} p_{2}\right), \\
p_{4}= & h f\left(x_{1}+\frac{12}{13} h, y_{1}+\frac{1932}{2197} p_{1}-\frac{7200}{2197} p_{2}+\frac{7296}{2197} p_{3}\right), \\
p_{5}= & h f\left(x_{1}+h, y_{1}+\frac{439}{216} p_{1}-8 p_{2}+\frac{3680}{513} p_{3}-\frac{845}{4104} p_{4}\right), \\
p_{6}= & h f\left(x_{1}+\frac{1}{2} h, y_{1}-\frac{8}{27} p_{1}+2 p_{2}-\frac{3544}{2565} p_{3}+\right. \\
& 18594104 p 4-1140 p 5 .
\end{aligned}
$$

The approximate solution by Runge Kutta $4^{\text {th }}$ order method is,

$y_{p+1}=y_{1}+\frac{25}{216} p_{1}+\frac{1408}{2565} p_{3}+\frac{2197}{4101} p_{4}-\frac{1}{5} p_{5}$.

The obtained approximate solution can be improved by utilizing the Runge Kutta $5^{\text {th }}$ order method as,

$z_{p+1}=y_{1}+\frac{16}{135} p_{1}+\frac{6656}{12825} p_{3}+\frac{28561}{56430} p_{4}-\frac{9}{50} p_{5}+\frac{2}{55} p_{6}$.

The solutions are obtained with an accuracy of $10^{-6}$ keeping the step size at 0.001 .

\section{Results and Discussion}

To understand the physical problem, the effect of relevant parameters on the fin thermal profile and efficiency has been plotted and discussed. Each parameter has been varied individually, keeping other parameters constant. The constant value of the parameters considered for the study are: $N c=1, N r=$ $1, m_{2}=1, m=2, \theta_{a}=0.4, G=0.1, \epsilon_{G}=$ 0.1 . For trapezoidal profile $C=0.4$ has been considered in the present analysis. 


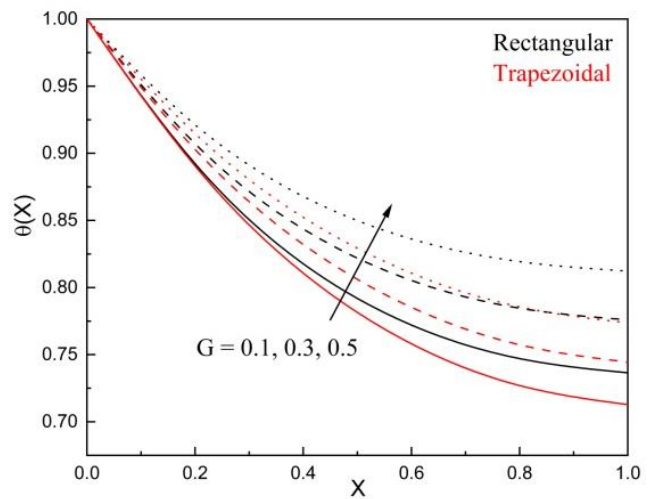

Figure 2: Fin temperature attribute for distinct values of generation number $G$.

The effect of variation of generation number $G$ on the distribution of temperature in trapezoidal and rectangular profiled fin is captured in figure 2 . It can be observed that, the parameter $G$ increases the distribution of temperature. This is due to increased heat gain within the fin structure. Thus, the fin cooling process is benefitted by lower values of $G$. Further, the temperature field of trapezoidal fin profile stays below the rectangular fin profile.

Impact of power index $m$ on the temperature profile of the longitudinal fin of two different profiles is as shown in figure 3. It is seen that the fin thermal profile is less steep for higher values of parameter $m$. Thus, lower values of $m$ are preferred for heat transfer enhancement in fin. Besides, the thermal profile of trapezoidal fin structure is steeper than that of rectangular fin structure.

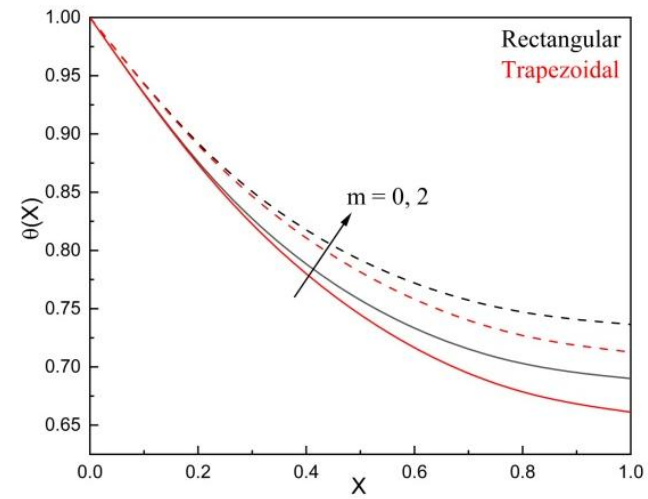

Figure 3: Fin temperature attribute for distinct values of power index $m$.

Figure 4 pictures the variation in the thermal profile of rectangular and trapezoidal profiled fins with the wet porous parameter $m_{2}$. The fin surface temperature decreases steeply towards the tip of the fin with increase in $m_{2}$ values. This is because, the porosity and wet conditions enhance the heat loss via convection supporting the fin cooling process. Thus, higher the values of $m_{2}$ higher will be the heat transfer rate. Further, the same trend is followed for trapezoidal and rectangular profiles.

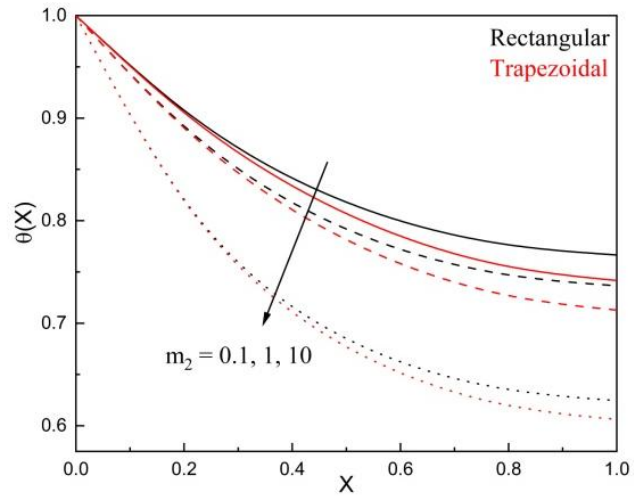

Figure 4: Fin temperature attribute for distinct values of wet porous parameter $m_{2}$.

Temperature profiles of various fin profiles for distinct values of convective parameter $\mathrm{NC}$ and radiative parameter $N r$ are captured in figure 5 and figure 6 respectively. It is noticed that the fin temperature sharply decreases with rise in the $N c$ and $N r$ values. This is due to increase in the heat loss through convection and radiation. Hence, ascending values of $\mathrm{Nc}$ and $\mathrm{Nr}$ enhance the heat transfer rate. On the other hand, the trapezoidal and rectangular profiles follow the similar trend.

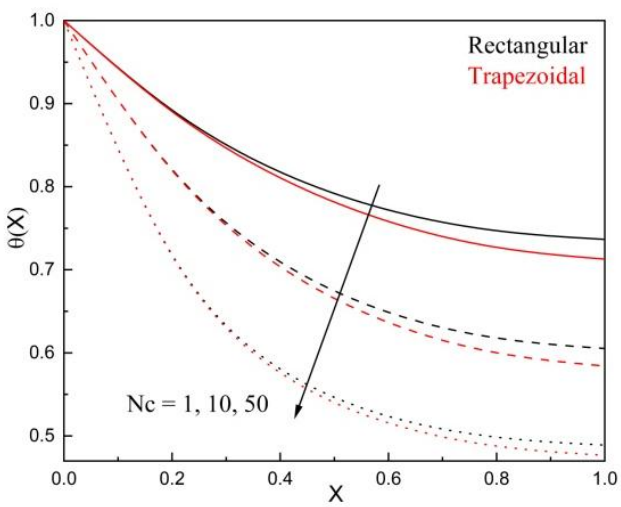

Figure 5: Fin temperature attribute for distinct values of Nc. 


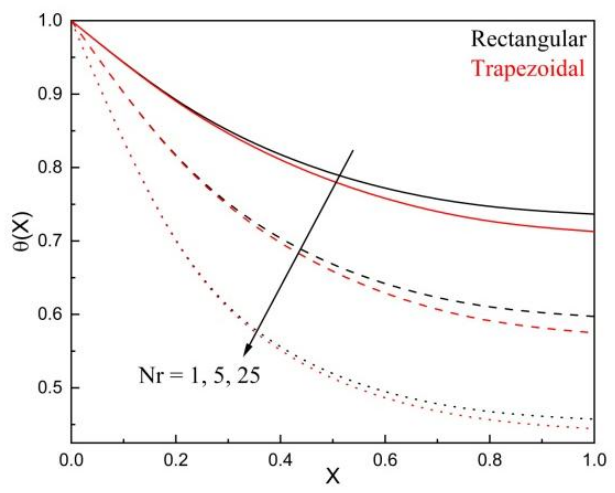

Figure 6: Fin temperature attribute for distinct values of $N r$.

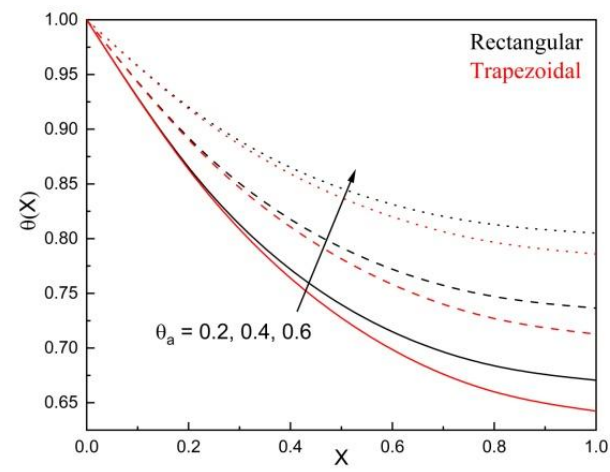

Figure 7: Fin temperature attribute for distinct values of ambient temperature $\theta_{a}$.

The consequence of ambient temperature $\theta_{a}$ on the thermal attribute of trapezoidal and rectangular fin profiles is as illustrated in figure 7. Higher the values of ambient temperature, higher are the fin surface temperature. This is because of negative impact on the convective heat loss resulting in rise in the surface temperature of the fin. Thus, lower values of ambient temperature enhance the fin cooling rate. Further, the surface temperature of trapezoidal fin profile is comparatively less than the rectangular profile.

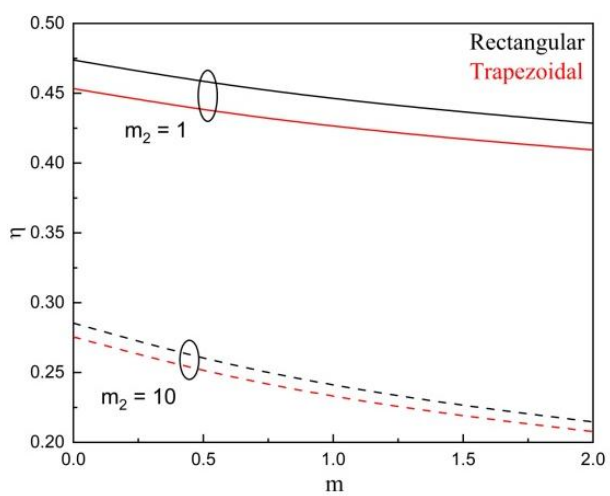

Figure 8: Variation in fin efficiency with power index $m$ and wet porous parameter $m_{2}$.
Figure 8 portrays the efficiency of trapezoidal and rectangular fin structures upon simultaneous variation of wet porous parameter $m_{2}$ and power index $m$. It is found that the fin efficiency decreases with rise in the values of $m$ and $m_{2}$. Thus, lower values of power index and wet porous parameter help in increasing the efficiency of fin structures.

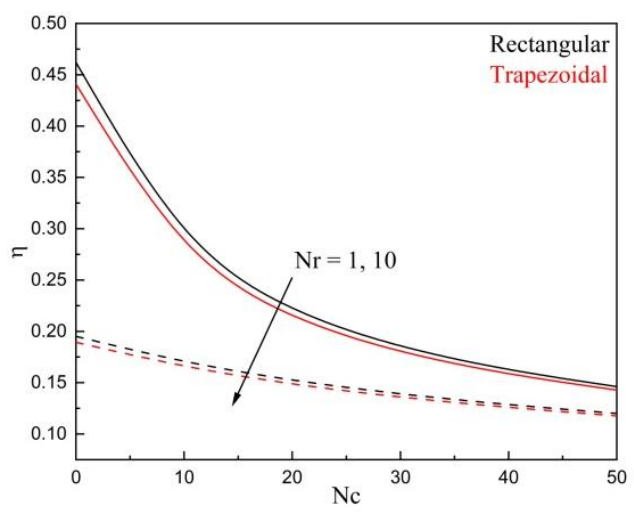

Figure 9: Variation in fin efficiency with $N c$ and $N r$.

The influence of convective parameter $N c$ and radiative parameter $\mathrm{Nr}$ on the efficiency of trapezoidal and rectangular profiled longitudinal fin structures is sketched in figure 9. The higher values of $N C$ and $N r$ negatively affect the fin efficiency. Hence, minimum values of convective and radiative parameters are preferred to enhance the fin efficiency.

In both figure 8 and figure 9 efficiency of rectangular fin profile is more than that of trapezoidal fin profile.

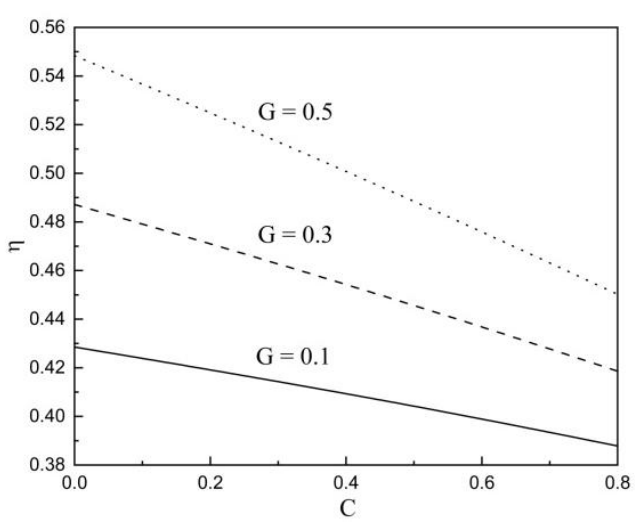

Figure 10: Variation in fin efficiency with generation number $G$ and fin taper ratio $C$.

Figure 10 outlines the dependence of fin efficiency on the generation number $G$ and fin 
taper ratio $C$. It is noted that higher values of generation number $G$ enhance the fin efficiency while higher values of fin taper ratio $C$ decrease the fin efficiency. Thus, higher values of $G$ and lower values of $C$ are preferred in enhancing the fin efficiency.

\section{Concluding Reviews}

The thermal behaviour of fully wet and porous longitudinal fin of trapezoidal profile exposed to convective and radiative heat losses has been studied in the present analysis. The following results have been revealed:

- The natural convection, radiation, porosity and fully wet nature have positive influence on the fin cooling process.

- The power index, generation number and ambient temperature values have to be kept at minimum to enhance the heat transfer.

- The heat transmission is higher in the case of trapezoidal fin than the rectangular fin.

- The convective parameter, power index, radiative parameter, fin taper ratio and wet porous parameter have negative influence on the efficiency of the fin structures.

- The increase in internal heat generation enhances the fin efficiency.

- Efficiency is higher in the case of rectangular profile than the trapezoidal profile.

\section{Nomenclature}

$\begin{array}{lll}A_{b} & = & \text { area of the fin base }\left(\mathrm{m}^{2}\right) ; \\ A(x) & = & \text { cross-sectional area of the fin at } \\ & \text { distance } x\left(\mathrm{~m}^{2}\right) ; \\ b_{2} & = & \text { variable parameter }(1 / \mathrm{K}) ; \\ C_{p} & = & \text { specific heat at constant pres- } \\ & \text { sure }(\mathrm{Jg} / \mathrm{K}) ; \\ C & = & \text { fin taper ratio; } \\ g & = & \text { acceleration due to gravity } \\ & \left(\mathrm{m} / \mathrm{s}^{2}\right) ; \\ G & =\text { generation number; }\end{array}$

\begin{tabular}{|c|c|c|}
\hline$h_{a}$ & $=$ & $\begin{array}{l}\text { heat transfer coefficient at } \\
\text { temperature } T_{a}\left(W / m^{2} K\right) \text {; }\end{array}$ \\
\hline$h$ & $=$ & $\begin{array}{l}\text { heat transfer coefficient } \\
\left(W / m^{2} K\right) \text {; }\end{array}$ \\
\hline$h_{D}$ & $=$ & $\begin{array}{l}\text { uniform mass transfer } \\
\text { coefficient; }\end{array}$ \\
\hline$k_{e f f}$ & $=$ & $\begin{array}{l}\text { effective thermal conductivity } \\
\text { of the material }(\mathrm{W} / \mathrm{mK}) \text {; }\end{array}$ \\
\hline$K$ & $=$ & permeability $\left(m^{2}\right)$ \\
\hline$L$ & $=$ & fin length $(m)$ \\
\hline$m$ & $=$ & $\begin{array}{l}\text { power index of heat transfer } \\
\text { coefficient; }\end{array}$ \\
\hline$m_{2}$ & $=$ & wet porous parameter; \\
\hline$m_{0}, m_{1}$ & $=$ & constants; \\
\hline $\mathrm{Nr}$ & $=$ & radiative parameter; \\
\hline$N c$ & $=$ & convective parameter; \\
\hline$q$ & $=$ & base heat transfer rate $(W)$ \\
\hline$Q$ & $=$ & dimensionless heat transfer rate; \\
\hline$t_{b}$ & $=$ & fin thickness at base $(m)$ \\
\hline$t(x)$ & $=$ & fin thickness at distance $x(m)$; \\
\hline$T$ & $=$ & fin surface temperature $(K)$ \\
\hline$T_{a}$ & $=$ & surrounding temperature $(K)$; \\
\hline$T_{b}$ & $=$ & base temperature $(K)$ \\
\hline$W$ & $=$ & width $(m)$ \\
\hline$x$ & $=$ & $\begin{array}{l}\text { axial coordinate of the fin }(m) \text {; } \\
\text { and }\end{array}$ \\
\hline$X$ & $=$ & non-dimensional length; \\
\hline
\end{tabular}

\section{Greek Symbols:}

\begin{tabular}{|c|c|c|}
\hline$\rho$ & $=$ & density $\left(\mathrm{kg} / \mathrm{m}^{3}\right)$; \\
\hline$\epsilon_{G}$ & $=$ & $\begin{array}{l}\text { dimensionless internal } \\
\text { generation parameter; }\end{array}$ \\
\hline$\phi$ & $=$ & porosity; \\
\hline$\theta_{a}$ & $=$ & $\begin{array}{l}\text { dimensionless } \quad \text { surround } \\
\text { temperature; }\end{array}$ \\
\hline$v$ & $=$ & kinematic viscosity $\left(\mathrm{m}^{2} / \mathrm{s}\right)$ \\
\hline$\delta$ & $=$ & $\begin{array}{l}\text { a geometrical quantity that de- } \\
\text { fines the tip semi-fin thickness } \\
(m) \text {; }\end{array}$ \\
\hline$\theta$ & $=$ & dimensionless temperature; \\
\hline$\sigma$ & $=$ & $\begin{array}{l}\text { Stefan-Boltzmann } \\
\left(\mathrm{W} / \mathrm{m}^{2} K^{4}\right)\end{array}$ \\
\hline$\omega_{a}$ & $=$ & $\begin{array}{l}\text { humidity ratio } \\
\text { surrounding air; }\end{array}$ \\
\hline
\end{tabular}




$\begin{aligned} i_{f g}= & \begin{array}{l}\text { latent heat of water evaporation } \\ (\mathrm{J} / \mathrm{kg}) ;\end{array} \\ \omega & =\begin{array}{l}\text { humidity ratio of the saturated } \\ \text { air; }\end{array} \\ \varepsilon \quad & \text { fin surface emissivity; } \\ \beta \quad & \text { volumetric thermal expansion } \\ & \text { coefficient }(1 / \mathrm{K}) .\end{aligned}$

Subscripts:

$\begin{aligned} S & =\text { solid. } \\ f & =\text { fluid; } \\ b & =\text { base; } \\ a & =\text { ambient; }\end{aligned}$

\section{References}

1. S. F. Al-Fahed and F. N. Alasfour, Rectangular Fin Thermal Performance as a Function of Modified Biot Number and Area Ratio; Novel Approach, International Journal of Scientific and Engineering Research, Vol. 10, No. 2, 2019, pp.550-556.

2. M. T. Darvishi, R. S. R. Gorla, F. Khani and B. J. Gireesha, Thermal Analysis Due to Natural Convection and Radiation in a Fully Wet Porous Fin, International Journal of Numerical Methods for Heat and Fluid Flow, Vol. 26, 2016, pp. 2419-2431. https://doi.org/10.1108/HFF-06-2015-0230.

3. R. Das, Estimation Of Feasible Materials and Thermal Conditions in a Trapezoidal Fin Using Genetic Algorithm, Proceedings of the Institution of Mechanical Engineers, Part G: Journal of Aerospace Engineering, Vol. 230, No. 13, 2016, pp. 2356-2368. https://doi.org/10.1177/0954410015623975.

4. R. S. R. Gorla and A. Y. Bakier, Thermal Analysis of Natural Convection and Radiation in Porous Fins, International Communications in Heat and Mass Transfer, Vol. 38, No. 5, 2011, pp.638-45.

https://doi.org/10.1108/HFF-06-2015-0230.
5. M. Hatami and D. D. Ganji, Investigation of Refrigeration Efficiency for Fully Wet Circular Porous Fins with Variable Sections by Combined Heat and Mass Transfer Analysis, International Journal of Refrigeration, Vol. 40, 2014,pp.140-151. 10.1016/J.IJREFRIG.2013.11.002.

6. R. Jooma and C. Harley, Heat Transfer in a Porous Radial Fin: Analysis of Numerically Obtained Solutions, Hindawi Advances in Mathematical Physics, Vol. 2017, 2017, pp.1-20. https://doi.org/10.1155/2017/1658305.

7. H. S. Kang, Analysis of Reversed Trapezoidal Fins using a 2-D Analytical Method, Universal Journal of Mechanical Engineering, Vol. 3, No. 5, 2015, pp.202-207. 10.13189/UJME.2015.030505

8. F. Khani and A. Aziz, Thermal Analysis of a Longitudinal Trapezoidal Fin with Temperature-Dependent Thermal Conductivity And Heat Transfer Coefficient, Communications in Nonlinear Science and Numerical Simulation, Vol. 15, No. 3, 2010, pp.590-601.

https://doi.org/10.1016/j.cnsns.2009.04.028.

9. S. Kiwan and M. A. Al-Nimr, using Porous Fins for Heat Transfer Enhancement, Journal of Heat Transfer, Vol. 123, No. 4, 2001, pp.790-795, https://doi.org/10.1115/1.1371922.

10. S. Kiwan, Effect Of Radiative Losses on the Heat Transfer from Porous Fins, International Journal of Thermal Sciences, Vol. 46, No. 10, 2007, pp.1046-1055. https://doi.org/10.1016/j.ijthermalsci.2006.11.0 13.

11. A. D. Kraus, A. Aziz and J. R. Welty, Extended Surface Heat Transfer, New York: John Wiley, Vol.54, No.5, 2002, https://doi.org/10.1115/1.1399680. 
12. B. Kundu, R. Das, P. A. Wankhade and K. S. Lee, Heat Transfer Improvement of a Wet Fin under Transient Response with a Unique Design Arrangement Aspect, International Journal of Heat and Mass Transfer, Vol. 127, 2018, pp.1239-1251.

https://doi.org/10.1016/j.ijheatmasstransfer.201 8.08.110.

13. M. L. Martins-Costa, V. Vendas Sarmento, A. Moraes de Lira and Rogério M. Saldanha da Gama, Temperature Distribution in Porous Fins, Subjected to Convection and Radiation Minimization of a Convex Functional, Hindawi Mathematical Problems in Engineering, Vol. 2020, 2020, pp.1-10. https://doi.org/10.1155/2020/8613717.

14. T. Onah, A. Nwankwo and E. N. Enugu, Design and Development of a Trapezoidal Plate Fin Heat Exchanger for the Prediction of Heat Exchanger Effectiveness, Journal of Energy Technologies and Policy, Vol. 9, No. 8, 2019, pp.2224-3232, 10.7176/JETP/9-8-03.

15. S. Panda, A Study On Nonlinear Wet Fin Problem using Homotopy Analysis Method, International Journal of Applied and Computational Mathematics, Vol. 3, 2017, pp.1487-1506, https://doi.org/10.1007/s40819016-0188-1.

16. P. K. Purwadi and M. Seen, Efficiency and Effectiveness of a Fin having the CapsuleShaped Cross Section in the Unsteady State, AIP Conference Proceedings, Vol. 2202, No. 1, 2019, https://doi.org/10.1063/1.5141705.
17. N. N. Sheikh, B. Kumar and N. K. Saini, A Review Paper On Pin Fin Efficiency Enhancement, International Journal of Applied Engineering Research, Vol. 14, No. 9, 2019, pp.108-112.

18. G. Sobamowo, O. M. Kamiyo and O. Adeleye, Further Study on Thermal Performance of Porous Fin With TemperatureDependent Thermal Conductivity and Internal Heat Generation Using Galerkin's Method of Weighted Residual, World Scientific News, Vol. 138, No. 2, 2019, pp.167-191.

19. G. Sowmya, B. J. Gireesha and M. Madhu, Analysis of a Fully Wetted Moving Fin with Temperature-Dependent Internal Heat Generation using the Finite Element Method, Heat Transfer, Vol. 49, No. 4, 2020, pp.193954. https://doi.org/10.1002/htj.21701.

20. M. Torabi, A. Aziz and K. Zhang, A Comparative Study of Longitudinal Fins of Rectangular, Trapezoidal, And Concave Parabolic Profiles With Multiple Nonlinearities, Energy, Vol. 51, 2013, pp. 243256.

https://doi.org/10.1016/j.energy.2012.11.052.

21. M. Turkyilmazoglu, Efficiency of the Longitudinal Fins Of Trapezoidal Profile in Motion, Journal of Heat Transfer, Vol. 139, No. 9, 2017, 094501.

https://doi.org/10.1115/1.4036328. 